\title{
Early post-operative complications of thyroid surgery- A study of 50 cases in a tertiary level hospital of Bangladesh
}

\author{
Dr. Md Shazibur Rashid \\ Associate Professor (CC) of Otolaryngology, Comilla Medical Collage. \\ Dr. Mohammad Al Mamun Hamid \\ IMO, Comilla Medical Collage Hospital. \\ Dr. Md Jahangir Alam Majumder \\ Associate Professor (CC) of Otolaryngology, Comilla Medical Collage. \\ Dr. Md Rafiqul Islam Sarkar \\ Associate Professor of Otolaryngology, Comilla Medical Collage. \\ Dr. Ratan Kumar Das Chawdhury \\ Professor of Otolaryngology, Comilla Medical Collage. \\ Dr Najnin Akhter \\ Assistant Professor of Paediatrics, Comilla Medical Collage.
}

Address of correspondence: Dr. Md Shazibur Rashid, Associate Professor (CC) of Otolaryngology, Comilla Medical Collage. Email-drsajiburrashid@gmail.com.

DOI: 10.31364/SCIRJ/v7.i6.2019.P0619664

http://dx.doi.org/10.31364/SCIRJ/v7.i6.2019.P0619664

\begin{abstract}
Objective:

To evaluate the early post-operative complications and the risk factors in relation to the extent of surgery in patients undergoing thyroidectomy in a tertiary level hospital.

Method: This was a cross-sectional observational study from 1st November 2017 to 30th April, 2018 in department of ENT \& HeadNeck surgery, Comilla Medical College Hospital, Comilla, 50 patients who underwent thyroid surgery were included this study.

Result: In total 50 patients' thyroid surgery were performed for different indications. The patients were between 21 - 60 years of age with a maximum incidence in 4th decade, out of them 42 patients were female and 8 patients were male with a female male ratio 5.25:1. Among the 50 patients, 27 patients were diagnosed as nodular goitre, 8 patients as papillary carcinoma, 11 patients as follicular adenoma \& 4 patients as follicular carcinoma. In this study papillary carcinoma is prevalent in 3rd decade and follicular carcinoma in 4th to 6th decade \& Nodular goitre 4th decade. Nodular goitre was the most frequent indications (54\%) which was followed by papillary carcinoma of thyroid (18\%). The only six complications noted in these 50 patients. Postoperative hematoma in 1 patient, transient hypocalcemia in 2 patients, unilateral RLN palsy in 2 patients and airway obstruction in 1 patient.
\end{abstract}

Conclusion:

For preventing early post-operative complications thorough anatomical knowledge and gentle operative technique is essential.

Keywords:

Complications of thyroidectomy, Hypocalcaemia, Recurrent laryngeal nerve palsy. Solitary thyroid nodule, Multinodular goitre. 


\section{Introduction:}

Thyroid surgeries comprise one of the more commonly performed procedures by a surgeon. Today most of the complications of thyroid surgery are related to either metabolic derangements or injury to the recurrent laryngeal nerve. Other complications include superior laryngeal nerve injury, infection, airway compromise and bleeding ${ }^{1}$. Early complication of thyroid surgery means complications up to the healing of wound.

Thyroidectomy as a frequent and relatively safe surgical procedure is associated with a minimal rate of complications. In fact, the focus of modern thyroidectomy, centers on potential morbidity from the procedure with emphasis on prevention of injury to closely investing structures such as the parathyroid glands and the recurrent laryngeal nerve ${ }^{2}$. As opposed to unilateral thyroid lobectomy, total thyroidectomy carries potential risk to all 4 parathyroid glands and both recurrent laryngeal nerves. Whereas parathyroid injury during unilateral thyroid lobectomy is unlikely to result in hypocalcemia. Postoperative hypocalcemia is a significant risk after total thyroidectomy. Similarly, although unilateral recurrent laryngeal nerve injury during thyroid lobectomy may have a significant impact on voice quality, bilateral recurrent laryngeal nerve injury during a total thyroidectomy has more serious airway consequences ${ }^{3,4}$. Therefore, it is essential to quantify the incidences of postoperative hypoparathyroidism and recurrent laryngeal nerve injury, and to identify potential predictive clinical factors for these morbidities. Such information is important to counsel the patients properly and determine preoperative risks for patients considering total thyroidectomy.

To minimize morbidity, it is recommended that these anatomical structures be recognize during surgery, moreover the surgeon should keep in mind anatomic variations of parathyroid glands and recurrent laryngeal nerves ${ }^{5,6}$. Experience of the operating surgeon and extent of surgery are important for the complication rate in thyroid surgery ${ }^{2}$.

Thyroidectomy is an effective and safe treatment modality with acceptable morbidity and even unrecorded mortality. Currently, the main postoperative complications of thyroidectomy are recurrent Laryngeal Nerve Palsy (RLNP) and hypoparathyroidism.

The etiology of postoperative hypoparathyroidism has been proven to be multifactorial, with the surgical technique, the revascularization and accidental resection of the parathyroid glands being the most significant factors ${ }^{7}$.

The type of thyroidectomy is contingent upon the benign or malignant features of lesion, size of the lesion, and degree of disability ${ }^{8}$. During the eighteenth century, the mortality rate of thyroid surgery was as high as $40 \%$ from hemorrhage and sepsis ${ }^{9}$. The advent of modern antiseptic, anesthetic facilities and improved surgical techniques along with better hemostatic and surgical instrumentation during the last century has tremendously contributed to the very low morbidity and mortality rates of modern thyroid surgery. Major postoperative complications of thyroid surgeries include wound infection, hematoma/ hemorrhage causing airway compromise, hypocalcemia, recurrent or superior laryngeal nerve injury, and thyroid storm. Precise knowledge of the intricate anatomic details and 
meticulous surgical technique are prerequisite determinants for successful outcomes and to keep complications within acceptable limits ${ }^{10}$.

Ramirez et al asserted that complications accompanying thyroid surgery are directly proportional to the extent of thyroidectomy and inversely proportional to the surgeon's experience ${ }^{11}$. The aim of this study was to assess the incidence of different early post operative complications of various thyroid surgeries done for benign as well as malignant $\&$ other thyroid disorders in a tertiary care center and to compare it with published data.

\section{MATERIALS AND METHOD}

This was a cross sectional observational study. The study was conducted in the Department of ENT and Head-Neck Surgery, Comilla Medical College Hospital, Comilla. The study was carried on for six month dated from 01-11-2017 to 30-04-2018. Sampling Method is Purposive Sampling and sample size is 50 . All the patients admitted with thyroid swellings requiring surgical management and willing for surgery included in this study. Patients were observed for complications up to 10 days.

All data were collected in case record forms (CRF), which was filled with history physical examination, investigations, operative procedure. Types of complication and management procedure used in Thyroid surgery.

\section{Results}

\section{Figure-1: Age Incidence}

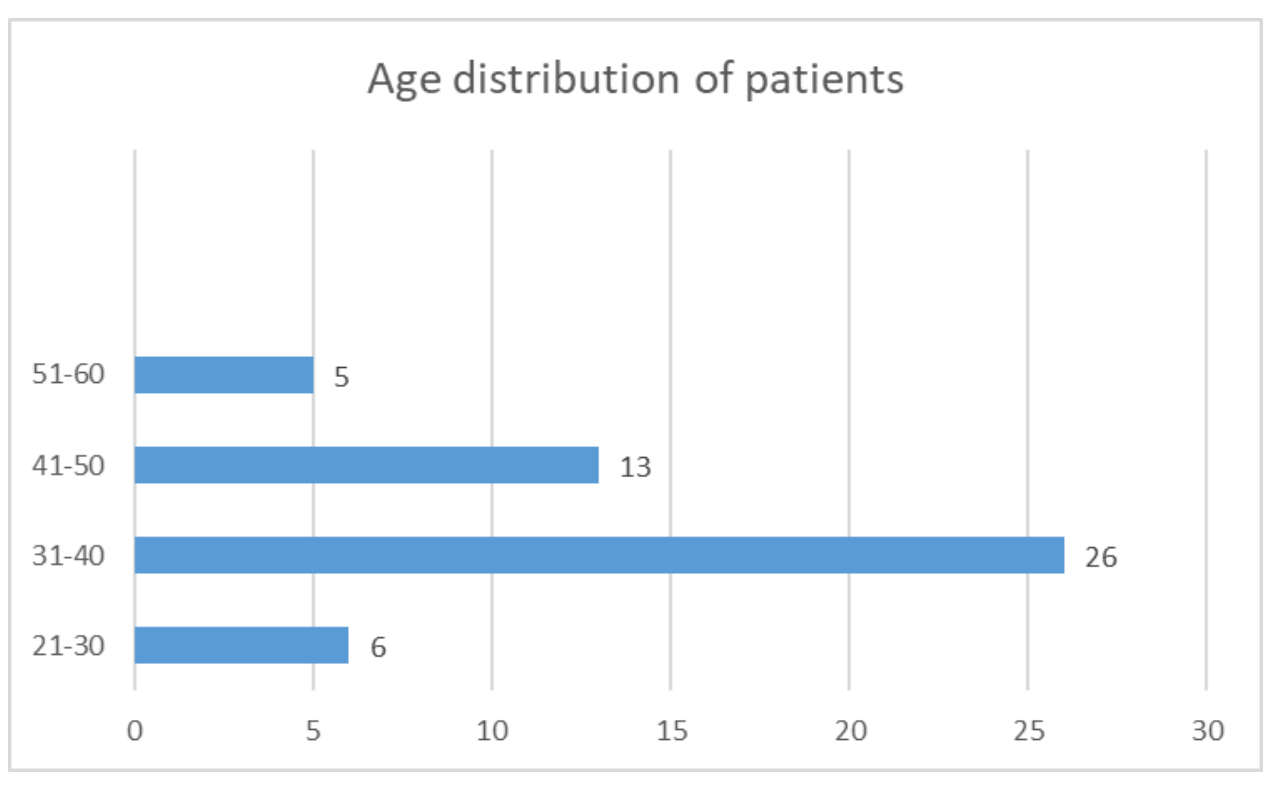

Figure-I shows most of the patients were in between 31 years to 50 years of age, with a maximum incidence in $3^{\text {rd }}$ and $4^{\text {th }}$ decades. In this series the mean age is $35.5 \pm 8.6$ years. 
Figure-2: Sex distribution of patients $(\mathbf{n}=\mathbf{5 0})$

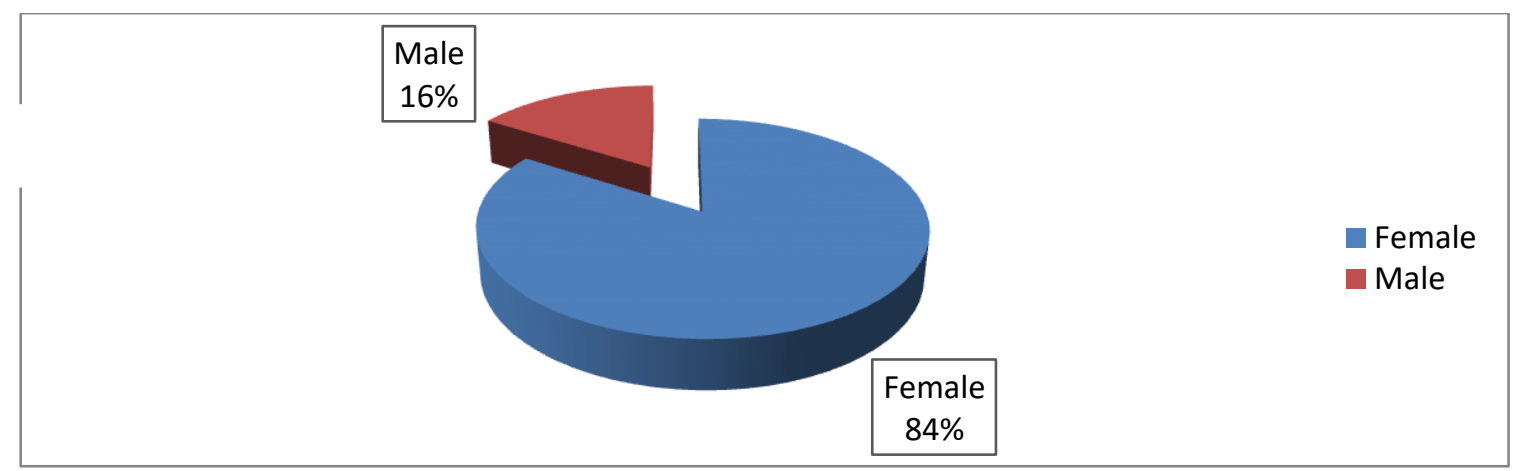

Figure 2 shows the distribution gender in the study groups. Out of total 50 patients 42 patients (84\%) were female and 8 patients (16\%) were male. female to male ratio in this series was 5.25:1.

Table-1: Presentation of thyroid swelling $(n=50)$

\begin{tabular}{|l|l|l|}
\hline Lobe distribution & Number of patients n=50 & Percentage \\
\hline Both lobe & 30 & $60 \%$ \\
\hline Right lobe & 11 & $22 \%$ \\
\hline Left lobe & 9 & $18 \%$ \\
\hline
\end{tabular}

Table 1 shows thyroid swelling affected both lobe in $60 \%$ cases.

Table-2: Goitre distribution

\begin{tabular}{|l|l|l|}
\hline Goitre distribution & Number of patients n=50 & Percentage \\
\hline Multinodular & $\mathbf{3 5}$ & $\mathbf{7 0 \%}$ \\
\hline Solitary nodule & $\mathbf{1 0}$ & $\mathbf{2 0 \%}$ \\
\hline Diffuse & $\mathbf{5}$ & $\mathbf{1 0 \%}$ \\
\hline
\end{tabular}

Table 2 shows multinodular goitre is $70 \%$ csase.

Table-3: Thyroid carcinoma distribution

\begin{tabular}{|l|l|l|}
\hline Thyroid carcinoma distribution & Number of Patients n=12 & Percentage \\
\hline Papillary & 8 & $66.67 \%$ \\
\hline Follicular & 4 & $33.33 \%$ \\
\hline
\end{tabular}

In this study Follicular carcinoma were found in $33.33 \%$ cases. 
Table-4: Histopathological Diagnosis $(n=50)$

\begin{tabular}{|l|l|l|}
\hline Types thyroid disease & Number of patients & Percentage \\
\hline Simple goitre & 27 & $54 \%$ \\
\hline Follicular adenoma & 11 & $22 \%$ \\
\hline Papillary carcinoma & 8 & $18 \%$ \\
\hline Follicular carcinoma & 4 & $8 \%$ \\
\hline
\end{tabular}

In this series out of 50 patients $54 \%$ had Nodular goiter, follicular adenoma $22 \%$, papillary carcinoma $18 \%$, Follicular carcinoma $8 \%$.

All cases were confirmed by histopathological examination following surgery.

Figure-3: Types of operations done in this study.

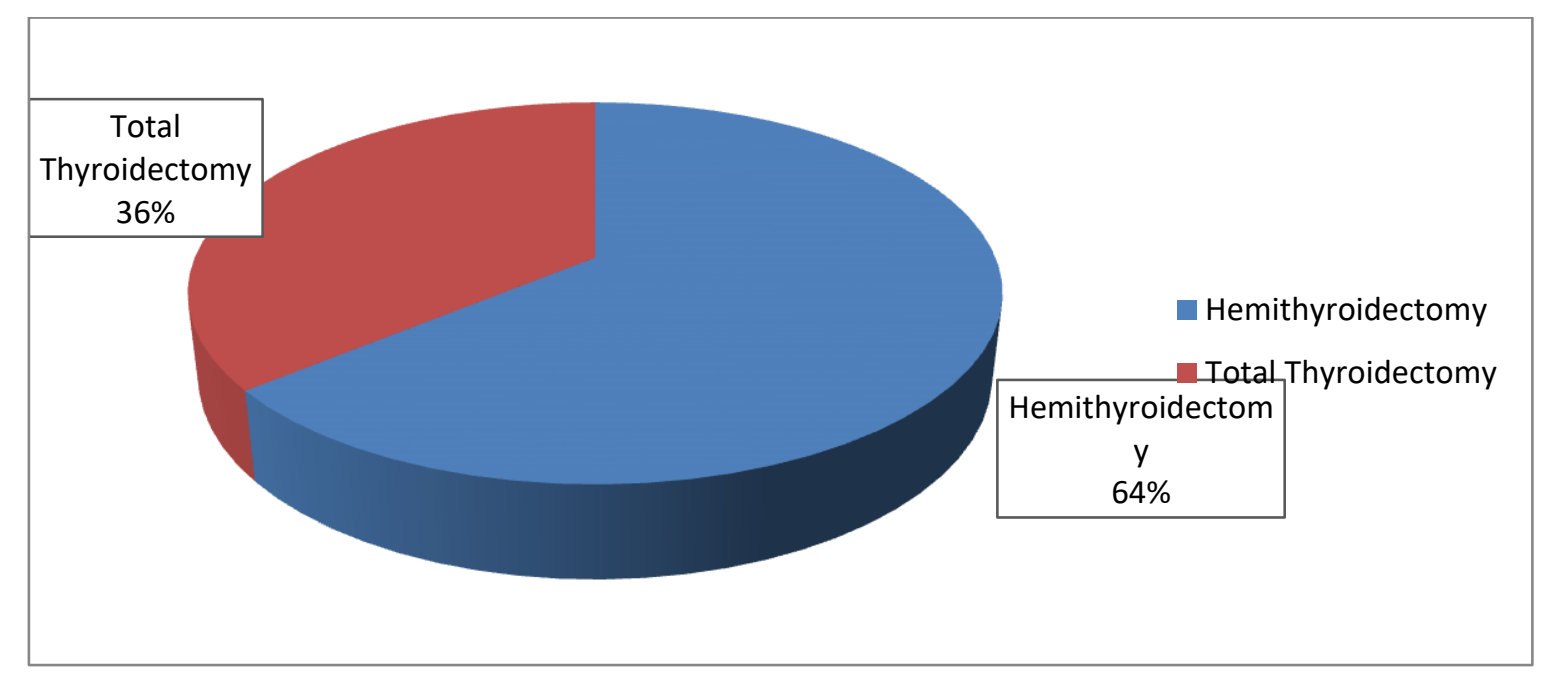

Figure-2 shows Hemithyroidectomy was done 32 number of patients (64\%) and total thyroidectomy was done 18 number of patient $(36 \%)$.

Table-5: Early post operative complications and their incidence

$(\mathbf{n}=\mathbf{5 0})$

\begin{tabular}{|l|l|l|}
\hline Type of Complications & No. of Patients & Percentage \\
\hline Postoperative haematoma & 1 & $2 \%$ \\
\hline Airway obstruction due to haematoma & 1 & $2 \%$ \\
\hline Unilateral recurrent laryngeal nerve palsy & 2 & $4 \%$ \\
\hline Transient Hypocalcaemia & 2 & $4 \%$ \\
\hline
\end{tabular}


Unilateral RLNP occurred in $1(2 \%)$. The rates of transient hypocalcaemia 2 number of patients (4\%). Postoperative hematoma occurred in 1 patient (2\%) and patient was reoperated on because of compressive symptoms and ongoing hemorrhage. In all case, drain was placed.

\section{DISCUSSION}

The operative management of thyroid disease is one of the major accomplishments of modern surgery. At present, the incidence of complications is quite low in thyroid surgery. Although the morbidity and mortality have declined markedly over the years. surgical complications remain a disappointing problem to surgeons ${ }^{11-13}$.

In our study, mean age was $35.5 \pm 8.6$ years, which is comparable to that reported by Shaikh, M S, from Larkana, Pakistan ${ }^{14}$ (mean age 36 years) while is contrast Veyseller observed mean age to be $42.6 \mathrm{yrs}^{15}$ and Ozbas (Turkey) $43.6 \mathrm{yrs}^{16}$. Due to better health facilities, more awareness, education and life expectancy of our region, there is difference in mean age with some other country.

Male female ratio on our study was 1:5.25, which is comparable to Imran's study form Karachi (M: F ratio as 1:3.8) ${ }^{17}$. In contrast, Hussain also form Karachi reported M: F ratio is 1:6.19 while Godara form India observed it to be 1:10.1 ${ }^{18,19}$.

In this Study, the involvement of both lobes was frequently noticed (60\%), followed by right lobe (22\%), which is comparable to Bekele's Study (Ethiopia) ${ }^{20}$ both lobes involved in $70 \%$ followed by right lobe $17.5 \%$. In contrast Iqbal's study revealed $64 \%$ right lobe involvement, followed by the left lobe ${ }^{21}$.

Our study revealed multinodular goiter in $70 \%$ cases, which was comparable to Hussain's Study $74.63 \%{ }^{18}$. In contrast Godara found multinodular goiter only in $15 \%$ cases with preponderance of solitary thyroid nodule in $68 \%{ }^{19}$. Solitary thyroid nodule was found in $20 \%$ of cases. So this means that prevalence of multinodular goiter is more in our region as compared to other parts of world. In this review malignancy was encountered in $24 \%$, comparable to Hussain's study, reporting $18.3 \%$ malignancy ${ }^{18}$. While in contrast Godara observed $8 \%$ malignancy and Rahman (Nigeria) 9.3\% 22 . In our study papillary carcinoma was diagnosed in $66.67 \%$, follicular carcinoma in $33.33 \%$ while Godara ${ }^{19}$ encountered papillary carcinoma in $75 \%$ and follicular carcinoma in $25 \%$. In contrast Hussain ${ }^{18}$ reported papillary carcinoma in $11.2 \%$ and follicular carcinoma in $1.8 \%$.

Thyroidectomy, one of the main forms of treatment for thyroid gland diseases, is performed worldwide by surgeons with varied background and expertise. The indications for surgery in these cases were suspicion of cancer, a massive goiter with symptoms of local compression, nodules with low radioiodine uptake (cold nodules) and patients desire for rapid and definitive treatment ${ }^{23}$. The extent of thyroidectomy in the management of thyroid diseases is a disputed issue among study and there is still no consensus as to how much thyroid tissue should be left behind ${ }^{24}$.

Subtotal thyroidectomy has been the gold standard for patients with benign thyroid diseases. The proponents of this technique suggest that leaving a small remnant of functional gland results in euthyroidism without the need for replacement therapy and is associated with a lower risk of damaging the recurrent laryngeal nerves and the parathyroid gland ${ }^{25,26}$. Nevertheless, the above approach has recently been challenged by endocrine surgeons who support total thyroidectomy and have demonstrated better control of thyroid disease and even comparable morbidity to subtotal thyroidectomy. Due to these encouraging reports, total thyroidectomy has gained 
acceptance among the surgeons involved in these study and over the last few years it has rapidly displaced the more conservative surgical approaches.

Recurrent laryngeal nerve palsy is the most serious complication in thyroid surgery, resulting in significant impairment of the quality of life and having a negative impact on job performance. In the present study, unilateral RLNP occurred in $4 \%$ cases. Dralle $\mathrm{H}$. et al ${ }^{27}$ concluded that routine visual nerve identification and preservation should be the gold standard in thyroid surgery. In this study, intraoperative nerve identification was the standard practice. Extensive resections, preoperative diagnosis of thyroid malignancy and recurrent goiter were identified as significant independent risk factors for RLNP in a recent study.

Postoperative hypoparathyroidism is a major concern leading to prolonged hospitalization and increased cost. In several studies, the incidence of transient hypocalcaemia varied from $6.9 \%{ }^{28}$ to $46 \%^{29}$. In the present study, transient hypocalcaemia occurred in 2 patients (4\%) and which was easily managed with oral supplementation of vitamin D and calcium supplementation. Clinical signs of hypocalcaemia requiring intravenous administration of calcium glouconate ware encountered in 1 patient $2.0 \%$.

Hematoma following thyroid surgery are rare event occurring in $<1 \%$ to $2 \%$ of all thyroidectomies ${ }^{30}$. Nevertheless, it can be a significant burden leading to airway obstruction, which is a surgical emergency. In our study hematoma was complication in 1 case $(2 \%)$ and reoperation was undertaken due to ongoing hemorrhage and airway obstruction.

\section{Conclusion}

This study was conducted to assess the outcome of various thyroid surgeries done in 50 patients admitted to the ENT and Head-Neck surgery wards of Comilla Medical College and Hospital, Comilla. The only six early post operative complications noted in these 50 patients. Postoperative hematoma in 1 patient, transient hypocalcemia in 2 patients, unilateral RLN palsy in 2 patients and airway obstruction in 1 patient. No case of permanent laryngeal nerve paralysis occurred in our study. Other complications like thyroid storm, wound infection, were not noticed in our study. It can be concluded that a good understanding of thyroid gland anatomy, improved techniques in hemostasis, RLN dissection, preservation of parathyroid glands and postoperative monitoring have caused steady decline in the incidence of postoperative complications following thyroidectomy. In addition, appropriate postoperative care with early identification of complications and prompt institution of corrective treatment plays an important role in reducing the duration of postoperative hospital stay and limiting patient morbidity.

\section{BIBLIOGRAPHY}

1. Sambasiva R.J. Clinical Study of Post-Operative Complications of Thyroidectomy. IOSR Journal of Dental and Medical Sciences.2016;15(9):20-26 
2. Lin DT, Patel SG, Shaha AR, Singh B, Shah JP. Incidence of inadvertent parathyroid removal during thyroidectomy. Laryngoscope 2002;112 (4): 608- 611.

3. Harness JK, Organ CHJ, Thompson NW. Operative experience of US general surgery residents in thyroid and parathyroid disease. Surgery. 1995; 118:1063-1070.

4. Bhattacharyya N, Fried MP. Benchmarks for mortality, morbidity and length of stay for head and neck surgical procedures. Arch Otolaryngol Head Neck Surg.2001;127:127- 132.

5. Lee NJ, Blakey JD, Bhuta S, Calcaterra TC. Unintentional parathyroidectomy during thyroidectomy. Laryngoscope 1999;109 (8): 1238- 1240.

6. Bhattacharyya NFried MP Benchmarks for mortality, morbidity and length of stay for head and neck surgical procedures. Arch Otolaryngol Head Neck Surg.2001;127:127- 132

7. Sasson AR, Pingpank JF, JrWetherington RW, Hanlon AL, Ridge JA. Incidental parathyroidectomy during thyroid surgery does not cause transient symptomatic $\quad$ hypocalcemia. Arch Otolaryngol Head Neck Surg 2001;127 (3): $304-308$.

8. Reeve T, Thompson NW, Complications of Thyroid Surgery: How to Avoid them, how to manage them, and observations on their possible effects on the whole Patient. World J Surg.2004; 24: 971-975.

9. Shah JP. Thyroid and parathyroids. Shah JP, editor. Head and neck surgery. New York: Mosby-Wolfe.1996;393-429.

10. Becker WF. Presidential address: pioneers in thyroid surgery. Ann Surg,1977;185(5):493-504.

11. Ramirez AT, Gibelli B, Tradati N, Giugliano G, Zurlo V, Grosso E, Chiesa F. Surgical management of thyroid cancer. Exp Rev Anticancer Ther. 2007: Sep;7(9):1203-1214.

12. Majid MA and Siddique MI, Major Post -operative complications of thyroid surgery: Preventable or not?

Bangladesh Med Res Counc Bull 2008; 34:99-103.

13. Shah JP. Thyroid and parathyroids. Shah JP, editor. Head and neck surgery. New

York: Mosby-Wolfe.1996:393-429.

14. Shaikh MS, Abro H, Dholia KR, Shaikh AS. Risks and complications of thyroid surgery: a 10 years' experience. J Surg Pak 2007; $12: 19-22$.

15. Veyseller B, et al. Total thyroidectomy in benign thyroid diseases. Kulak Burun Bogaz Ihtis Derg 2009; 19:299-303.

16. Ozbas S, at el, Comparison of the complications of subtotal, near total and total thyroidectomy in the surgical management of multinodular goiter. Endocr J 2005;52:199-205.

Www.scirj.org 
17. Imran AA, at el, Diagnosis of enlarged thyroid- an analysis of 250 cases. Ann KE Med Coll 2005;11:203-204.

18. Hussain N, at el, Patterns of surgically treated thyroid disease in Karachi. Biomedica. 2005; 21:18-20.

19. Godara R, Garg P, Singla S. Thyromegaly: Lack of consensus in Management. [Online].2007[cited2007March23];Availablefrom:URL:http://www.ispub.com/journal/the-internet-journal-ofsurgery/volume-10number-1/thyromegaly-lack-

20. Bekele A, Osman M, Goiter in Teaching Hospital in North Western Ethiopia. East Cent Afr J Surg, 2006;11:21-7.

21. Chow TL, at el, outcome and complication of thyroid surgery. HKMJ, Hong Kong, 2006;7:261-265.

22. Rahman GA, at el, Thyroid cancers amongst goiter population in a Nigerian tertiary hospital: surgical and radiographic perspective. Niger J Med 2010; 19:432-5.

23. Pandey AK, Maithani T, Agrahari A, Varma A, Bansal C, Bhardwaj A, Singh VP, Rathi S. Postoperative Complications of Thyroid Surgery: A Corroborative Study with an Overview of Evolution of Thyroid Surgery. Int J Head Neck Surg 2015;6(4):149-154.

24. Spiliotis J, at el Diagnosis of thyroid cancer in southwestern Greece. Bull Cancer. 2013;78:953-959.

25. Hurley DL, Gharib H, Evaluation and management of multinodular Goiter. Otolaryngon Clin North Am. 2008; 29: 527-540.

26. Miccoli P, Vitti P, Rago T, et al, Surgical treatment of Graves' disease: subtotal or total thyroidectomy? Surgery. 1996; 120: 1020-1025.

27. Dralle H, Sekulla C, Haerting J, et al, Risk factors of paralysis and functional outcome after recurrent laryngeal never monitoring in thyroid surgery. Surgery. 2004;136: 1310-1322.

28. Barakate MC, at el, Total thyroidectomy is now the preferred option for thesurgical management of Graves' disease. ANZ J Surg. 2002; 72:321-324.

29. Steurer M, at el, Advantage of recurrent laryngeal nerve identification in thyroidectomy and parthyroidectomy and the importance of preoperative and postoperative laryngoscopic examination in more than 1000 nerves at risk. Larnygoscope. 2004;112:124-133.

30. Smith E, at el, Effect of voice disorders on quality of life. J Med Speech- Language Pathol. 1996;4:223-244. 